\title{
Using Casual Loop Diagramming to Explore the Drivers of Web Development
}

\author{
Liu Chang ${ }^{1}$, Seong-Taek Park ${ }^{2}$ and Jia Yongfei $^{3}$ \\ ${ }^{1}$ Professor, Department of logistics management and engineering, Taisan University, China \\ 2 Professor, Department of MIS, Chungbuk National University, South Korea \\ ${ }^{3}$ Professor, Institute of Science and Technology Development, Shandong Academy of Sciences, China
}

\begin{abstract}
Background/Objectives: This paper proposes the basic analytical framework of web development systems from the perspective of system dynamics. Methods/Statistical analysis: Based on the feedback characteristic of web development activities, we analyze the causality in the web development from six aspects including work stress, web development, motivation, developer maintenance, recruitment and outsourcing and create a casual loop diagram of web development. Through system analysis, crucial factors needed for web developers to accomplish web development tasks continuously and stably are illuminated. Findings: The results show that external variables such as new recruitment and case outsourcing can have a short-term effect on the system, while internal variables such as work motivation and work stress have a greater influence on web development activities, which will result in a fluctuation of job performance. Improvements/Applications: From the perspective of management, countermeasures are put forward on how to mobilize the enthusiasm and initiative of developers and improve productivity.
\end{abstract}

\section{Index Terms}

Web Development, Systems Thinking, Causal Loop Diagrams

Corresponding author: Jia Yongfei

jiayongfei1983@126.com

- Manuscript received July 14, 2018.

- Revised August 14, 2018 ; Accepted September 7, 2018.

- Date of publication September 30, 2018. 


\section{INTRODUCTION}

With the rapid development of web applications, information processing has also evolved from the centralized model to the distributed one [1]. Web services emerge under such circumstance. Characterized by encapsulation, loose coupling, selfdescription, interoperability and universality [2], web services have a widespread application in many areas. Web services refer to the free interaction of software components via the network, which should be premised on meeting users' needs. The demand for web services is growing day by day and a new paradigm is taking shape in business process applications [3].

Web services have attracted widespread attention from the industry and academia and many researchers have studied on it from different perspectives. For example, some scholars have made researches on the machine, system and software fields such as web operation, web security, interface quality, high-quality code development [4], automatic keyword extraction [5], prevention of web fault propagation [6], web accessibility [7] and web design usability [8]. Based on web service, other scholars have evaluated the web application of end-user portfolio [9] and the web user generated contents [10] and have developed the web service recommendation system [11] .

According to the existing research results, scholars' researches focus more on system, software and program development and less on dynamic and integral analysis.

System thinking is an interdisciplinary approach to understanding the capability and structure of complex systems [12]. It is suggested that system thinking focuses on the analysis of the relations between each part of the system rather than the function of each component. It aims to improve the system behavior by finding out key indicators within the system [3]. System dynamics is a sub-branch of system thinking [14].

Based on the concept of change and circulation, system dynamics shows us the complex relations among variables through simulations and computerbased models, which will be a great help in constructing hypotheses and evaluating system behavior. Meanwhile, it also helps monitor the effects of subsystem changes and shows the relationships between elements in a graphical format [15].

System dynamics understand the complex system behaviors through qualitative tools and quantitative tools. Qualitative tools are of great use in describing the problem and the root cause for problems as well as finding out potential solutions. Quantitative tools are also very useful in visualizing the system through mathematical modeling and in analyzing the different effects brought by different measures we take [16].

According to Forrester (1987) and Sterman (2000), quantitative modeling can enhance people's understanding on complex systems. However, Vennix (1999) [18] and Mirchi (2012) point out that qualitative modeling is conducive to improving the understanding on the root cause of problems and gather information to define and solve complex problems.

\section{METHODOLOGY}

\section{A. Identification of key elements in web development systems}

This paper uses qualitative research strategy when choosing factors that affect web development, while qualitative research is to find out key performance indicators of the system by sorting out all papers about web development, work experience of web developers, work performance and web service feedbacks [19].

Scholars agree that there is a casual relationship between employees' behaviors or attitudes and the organizational performance. Kehoe and Wright (2013) have conducted a survey on the 56 independent business units of a large food service organization, results of which prove that employee's behaviors and attitudes have a great impact on their performance [20].

Employees will work hard when they are able to and expect to fulfil the task assigned to him [21]. On the one hand, a professional web developer will not explore his or her potentials without motivations. On the other hand, an inexperienced web developer will also achieve less in web development. However, a motivated and experienced web developer will also not be able to complete the task without a positive technical environment.

All of the external variables that affect individual performance revolve around the configurations and tasks of web developers, thus improving job performance. At the same time, all these factors or variables are out of human control [22]. Based on literature review, this paper believes that work stress, web development experience, motivation, developer maintenance, recruitment and outsourcing are the key performance indicators that affect web development systems.

Table 1 summarizes relevant literatures on web development from different aspects, according to which, we find that many web development researches can fall into four categories including web page development, technical design, web service and web developers, and multi-dimensional (combination 
of the above three aspects) researches.

Technical researches mainly focus on web design [23], web access [24], and web system development [26]. While web service researches focus on personalized web development, personalized dynamic configuration of files, dynamic User profiles[28], high-quality code-first web service[29] and Personalized Collaborative Filtering for Web Service[30]. While web developer researches focus on the working environment for Web Developers [31], the needs, problems and the processes that developers follow [32] and web application comprehension [33]. The literature review summarized in Table 1, allowed identifying seven causes for the web development process [23-33].

Table 1 Studies Included in the Analysis of Web DEVELOPMENT

\begin{tabular}{|c|c|c|}
\hline Aspect & Component & Reference \\
\hline Technical & $\begin{array}{l}\text { Process/Tec } \\
\text { hnology }\end{array}$ & $\begin{array}{l}\text { Flanagin et al.(2014); } \\
\text { Liu et al.(2015); } \\
\text { Aizpurua et al.(2016); } \\
\text { Perdomo et al.(2017) }\end{array}$ \\
\hline $\begin{array}{l}\text { Web } \\
\text { Service }\end{array}$ & $\begin{array}{l}\text { System/Serv } \\
\text { ice } \\
\text { Personalizati } \\
\text { on }\end{array}$ & $\begin{array}{l}\text { Lorena and Villegas } \\
\text { (2014); Hawalah and } \\
\text { Fasli (2015); Roriguez } \\
\text { et al. (2015); Liu et } \\
\text { al.(2016) }\end{array}$ \\
\hline $\begin{array}{l}\text { Managemen } \\
\mathrm{t}\end{array}$ & $\begin{array}{l}\text { Developmen } \\
\mathrm{t} \\
\text { environment } \\
\text { / } \\
\text { Developers' } \\
\text { Experience }\end{array}$ & $\begin{array}{l}\text { Rosson et al.(2005); } \\
\text { Rosson and Kase } \\
(2008) ; \text { Ricca et al. } \\
(2010)\end{array}$ \\
\hline
\end{tabular}

\section{B. Building of systemic relationships}

Based on the definition and analysis of the web development system, we divide it into several parts including the work stress sub-model, web development activities sub-model, work motivation sub-model and web developers maintenance submodel, web developers recruitment sub-model and outsourcing sub-model.

Casual analysis is conducted on those sub-systems. Figure 1 shows the simplified version of the systematic qualitative model. This causal loop diagram shows six correlative feedback loops which determined the dynamic behavior of the models. There are some labels such as R1, R2, R3, B1, B2 and $\mathrm{B} 3$, among which, "R" stands for "strengthening" or "positive feedback loop", while "B" means "balance" or negative feedback loop.

\section{R1: work stress loop}

As an important part of web application, the interface has a direct effect on user experience [34]. Web developers should be user-oriented and meet the differentiated demands of users. Web contents design involves many areas such as network technology, visual effect and web page economics.

With similar functions, those web pages are similar in components, layout and styles. Repeated coding work will significantly reduce web developers' efficiency and weaken enterprises' upgrading capacity. Growing work stress will sap web developers' enthusiasm for the work and lead to more absenteeism, sick leave and lower productivity. While lower productivity increases the workload, which results in greater pressure that further saps their enthusiasm for the work.

\section{R2: Web development activities loop}

Web development activities can be affected by many factors such as web development tools, web developers' technical strength, working style and individual characters and even the age [31].

As documented in our previous analyses, web development takes place in a wide range of contexts. Web developers' professional knowledge and how much time they were willing to spend on the work have a direct effect on the improvement of productivity. The more cases developers' process, the experienced they will be and the higher the productivity will be. As a result, a simple and obvious virtuous circle will be formed.

\section{R3: work motivation loop}

AMO (ability, motivation, and opportunity) theory believes that there are three mechanisms in human resource management that affect employee's performance. First, human resource management affects employees' capacity of completing the tasks. Employees' demand for the knowledge, skills and capacity shall be met. Second, human resource management has influence on the motivation of completing the tasks. It means that employees who have fulfilled tasks should be awarded and told what kind of behaviors are expected and supported by the company. Third, opportunities also have a great effect on performance. Of course, employees' physical and psychological conditions also make a difference to 
their motivations.

Whether developers can work as a team or even feel the lack of professional knowledge during the web development depends on their self-recognition of the current work, which is a kind of cognition based on their satisfaction for the current job and working environment. Those factors are also affected by developers' work motivation. Therefore, a virtuous circle will be formed.

\section{B1: Web developers keeping loop}

Under great pressure and heavy work load, staffs are less motivated and become unsatisfied with their work and the working environment. Thus, they are more likely to leave the company. enhance their satisfaction for the work and prevent the structure from turning into a vicious circle.

\section{B2: Web developers' recruitment loop}

A solution to alleviate work stress is to provide trainings for web developers, which will make them more proficient in their work. Another approach is to recruit more web developers. From B1 paragraph, we've learnt that recruitment may be a delay for the staff turnover, because it will take three or six months to recruit a qualified web developer.

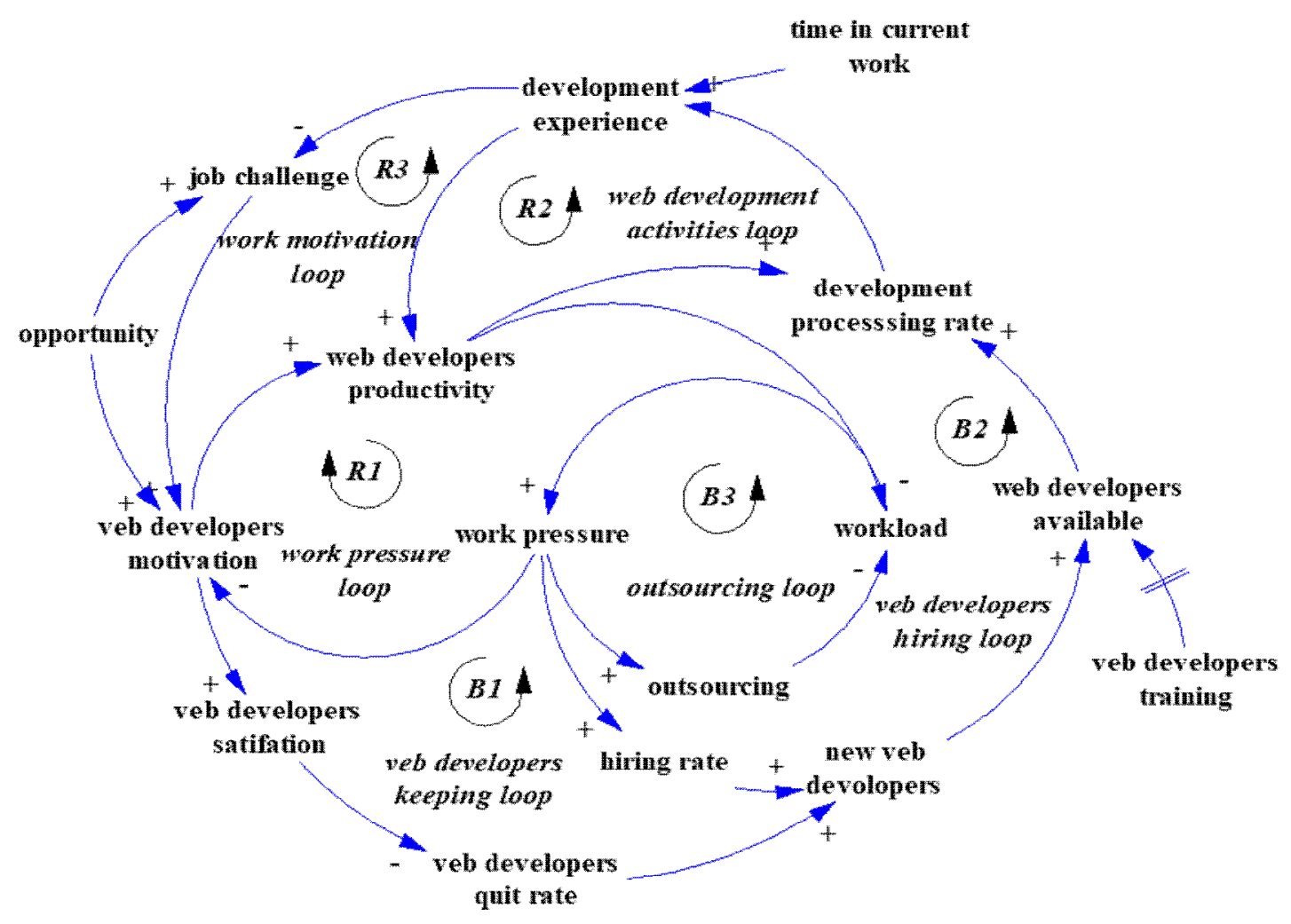

Figure 1 Causal loop diagram for the web developer framework(the signs \pm indicate positive/negative influence respectively).

However, high quit rate will lower the productivity. This problem is often solved by recruiting more web developers. But the recruitment of web developers is a long-term work and cannot be achieved in a short time. Therefore, in order to avoid the loss of more web developers, we need to create a better working environment and reduce their workloads so as to
Moreover, if you want to have a competent web developer who fully devotes himself or herself to the development and design work, you'll have to spend at least one or three years in cultivating him or her by getting to know his or her habits of internet use, personal traits and way of work.

\section{B3: Outsourcing loop}

Outsourcing part of web development work to other companies is a short-term solution to respond to work stress. 
Outsourcing brings many benefits to companies such as streamlining organizations, reducing costs, acquiring professional services and making a quick response to the market demand. Therefore, outsourcing has become the mostly used strategy over the past two decades.

However, outsourcing, in fact, is a special company relationship between self-production and procurement, which may bring more unpredictable risks to the companies.

\section{RESULT AND DISCUSSION}

In order to explore issues around Web specification processes and what characteristics are typically included in these specifications, we undertook an extensive set of industry interviews and surveys, followed by a detailed analysis of a number of commercial specifications. The interviews were primarily intended to identify general perceptions and qualitative trends, while the surveys captured more quantitative information.

The specification analysis was intended to extract detailed information on the structure and contents of commercial Web system specifications. The overall goal was to understand current best-practice in the specification of Web systems. This paper makes an analysis on web development through a casual loop diagram, a tool often used in system dynamics.

It offers us a visual alternative to show the complexity of systems, including elements of various sub-systems and the relationship among the elements. As shown in figure 1, there are six sub-systems that affect web development systems, including the work stress sub-model, web development activities submodel, work motivation sub-model, web developers' maintenance sub-model, web developer recruitment sub-model and outsourcing sub-model.

The six sub-systems consist of 16 interactive elements. Among them, the most critical ones are work stress sub-model and work motivation submodel, because they are closely related to web developers' work state and productivity.

Using the casual loop diagram to evaluate web development is proved to be appropriate.

Furthermore, the casual loop diagram establishes a platform for the construction of systematic models, which allows all stakeholders to share their opinions, learn from each other and have a comprehensive understanding on their systems.

By using the qualitative research strategy, an analysis on web development systems is conducted to exam the system in a comprehensive way. It helps to further collect information and to carry out more researches, aiming to find more evidence for encouraging the use of qualitative research strategy.
Results show that a long-term cooperative outsourcing relationship should be established between companies and outsourcing companies, which will reduce transaction costs, conflicts and outsourcing risks.

In addition, managers should be aware that measures such as staff trainings and web developer recruitment are effective in the short term. However, in the long run, companies should focus more on human resource management policies.

For example, they should cultivate staff's knowledge, skills and capacities and mobilize their enthusiasm for the work. More importantly, companies should pay close attention to staff's contribution by fully supporting web developers and offering them powerful code editing tools or WYSIWYG facilities.

\section{REFERENCES}

[1] Papazoglou, M. P. (2003, December). Service-oriented computing: Concepts, characteristics and directions. In Web Information Systems Engineering, 2003. WISE 2003. Proceedings of the Fourth International Conference on (pp. 312). IEEE.

[2] Erl, T. (2004). Service-Oriented Architecture: A Field Guide to Integrating XML and Web Services, Prentice Hall PTR, NJ, USA.

[3] Kalpana, R., Saruladha, K., \& Jayabharathy, J. (2016). Studying the Performance of QoS Specific Web Service Recommendation System Using Virtural Regions. J. Web Eng., 15(5\&6), 397-411.

[4] Rodriguez, J. M., Mateos, C., \& Zunino, A. (2015). Assisting developers to build high-quality code-first Web Service APIs. J. Web Eng., 14(3\&4), 251-285.

[5] Li, L., Su, C., Sun, Y., Xiong, S., \& Xu, G. (2015, October). Hashtag biased ranking for keyword extraction from microblog posts. In International Conference on Knowledge Science, Engineering and Management (pp. 348-359). Springer, Cham.

[6] Liu, Y., Mao, S., Zhang, M., Liu, G. Q., Zhu, Z., \& Cheng, J. (2015). Prevention of Fault Propagation in Web Service: a Complex Network Approach. J. Web Eng., 14(1\&2), 136150.

[7] Aizpurua, A., Harper, S., \& Vigo, M. (2016). Exploring the relationship between web accessibility and user experience. International Journal of Human-Computer Studies, 91, 13-23.

[8] Perdomo, E. G., Cardozo, M. T., Perdomo, C. C., \& Serrezuela, R. R. (2017). A Review of the User Based Web Design: Usability and Information Architecture. International Journal of Applied Engineering Research, 12(21), 11685-11690.

[9] Lizcano, D., Alonso, F., Soriano, J., \& López, G. (2014). A component-and connector-based approach for end-user composite web applications development. Journal of Systems and Software, 94, 108-128.

[10] Momeni, E., Cardie, C., \& Diakopoulos, N. (2016). A survey on assessment and ranking methodologies for user-generated content on the web. ACM Computing Surveys (CSUR), 48(3), 41.

[11] Anithadevi, N., \& Sundarambal, M. A design of intelligent QoS aware web service recommendation system. Cluster Computing, 1-10.

[12] Sterman, J. D. (2000). Business dynamics: systems thinking and modeling for a complex world (No. HD30. 2 S7835 2000).

[13] Hjorth, P., \& Bagheri, A. (2006). Navigating towards sustainable development: A system dynamics approach. Futures, 38(1), 74-92. 
[14] Stave, K. A. (2002). Using system dynamics to improve public participation in environmental decisions. System Dynamics Review: The Journal of the System Dynamics Society, 18(2), 139-167.

[15] Chaerul, M., Tanaka, M., \& Shekdar, A. V. (2008). A system dynamics approach for hospital waste management. Waste management, 28(2), 442-449.

[16] Mirchi, A., Madani, K., Watkins, D., \& Ahmad, S. (2012). Synthesis of system dynamics tools for holistic conceptualization of water resources problems. Water resources management, 26(9), 2421-2442.

[17] Forrester, J. W. (1987). Lessons from system dynamics modeling. System Dynamics Review, 3(2), 136-149.

[18] Vennix, J. A. (1999). Group model-building: tackling messy problems. System Dynamics Review: The Journal of the System Dynamics Society, 15(4), 379-401.

[19] Goodenough, A., \& Waite, S. (2012). Real world research: a resource for users of social research methods in applied settings.

[20] Kehoe, R. R., \& Wright, P. M. (2013). The impact of highperformance human resource practices on employees' attitudes and behaviors. Journal of management, 39(2), 366391.

[21] Delaney, J. T., \& Huselid, M. A. (1996). The impact of human resource management practices on perceptions of organizational performance. Academy of Management journal, 39(4), 949-969.

[22] Blumberg, M., \& Pringle, C. D. (1982). The missing opportunity in organizational research: Some implications for a theory of work performance. Academy of management Review, 7(4), 560-569.

[23] Perdomo, E. G., Cardozo, M. T., Perdomo, C. C., \& Serrezuela, R. R. (2017). A Review of the User Based Web Design: Usability and Information Architecture. International Journal of Applied Engineering Research, 12(21), 11685-11690.

[24] Flanagin, A. J., Hocevar, K. P., \& Samahito, S. N. (2014). Connecting with the user-generated Web: how group identification impacts online information sharing and evaluation. Information, Communication \& Society, 17(6), 683-694.

[25] Aizpurua, A., Harper, S., \& Vigo, M. (2016). Exploring the relationship between web accessibility and user experience. International Journal of Human-Computer Studies, 91, 13-23.

[26] Liu, Y., Mao, S., Zhang, M., Liu, G. Q., Zhu, Z., \& Cheng, J. (2015). Prevention of Fault Propagation in Web Service: a Complex Network Approach. J. Web Eng., 14(1\&2), 136150.

[27] Castañeda, L., Villegas, N. M., \& Müller, H. A. (2014, June). Self-adaptive applications: On the development of personalized web-tasking systems. In Proceedings of the 9th International Symposium on Software Engineering for Adaptive and Self-Managing Systems (pp. 49-54). ACM.

[28] Hawalah, A., \& Fasli, M. (2015). Dynamic user profiles for web personalisation. Expert Systems with Applications, 42(5), 2547-2569.

[29] Rodriguez, J. M., Mateos, C., \& Zunino, A. (2015). Assisting developers to build high-quality code-first Web Service APIs. J. Web Eng., 14(3\&4), 251-285.

[30] Liu, J., Tang, M., Zheng, Z., Liu, X. F., \& Lyu, S. (2016). Location-aware and personalized collaborative filtering for web service recommendation. IEEE Transactions on Services Computing, 9(5), 686-699.

[31] Rosson, M. B., \& Kase, S. (2006, September). Work, play, and in-between: Exploring the role of work context for informal web developers. In Visual Languages and HumanCentric Computing, 2006. VL/HCC 2006. IEEE Symposium on (pp. 151-156). IEEE.

[32] Rosson, M. B., Ballin, J. F., Rode, J., \& Toward, B. (2005, July). "Designing for the web" revisited: a survey of informal and experienced web developers. In International Conference on Web Engineering (pp. 522-532). Springer, Berlin, Heidelberg.
[33] Ricca, F., Di Penta, M., Torchiano, M., Tonella, P., \& Ceccato, M. (2010). How developers' experience and ability influence web application comprehension tasks supported by uml stereotypes: A series of four experiments. IEEE Transactions on Software Engineering, 36(1), 96-118.

[34] Zhu, S. S., Liu, W. H., Cai, J. M., \& Liu, M. W. (2015). The research and design of the web page information system editor. 